Service social

\title{
Dictionnaire de la recherche scientifique, par Richard Lefrançois, Lennoxville, Les Éditions Némésis, 1991, 220 pages.
}

\section{Francine Ouellet}

Volume 40, numéro 2, 1991

Formation et évolution de la pratique en travail social

URI : https://id.erudit.org/iderudit/706533ar

DOI : https://doi.org/10.7202/706533ar

Aller au sommaire du numéro

Éditeur(s)

École de service social de l'Université Laval

ISSN

1708-1734 (numérique)

Découvrir la revue

Citer ce compte rendu

Ouellet, F. (1991). Compte rendu de [Dictionnaire de la recherche scientifique, par Richard Lefrançois, Lennoxville, Les Éditions Némésis, 1991, 220 pages.] Service social, 40(2), 147-147. https://doi.org/10.7202/706533ar d'utilisation que vous pouvez consulter en ligne.

https://apropos.erudit.org/fr/usagers/politique-dutilisation/ 
I'initiative de Deslauriers arrive à point nòmmé. Ouvrage de référence pour quiconque s'intéresse au renouvellement des méthodes de recherche en sciences sociales, ce livre est également d'intérêt pour les intervenantes et les intervenants soucieux d'améliorer leur démarche d'intervention par la systématisation de leurs activités de collecte et d'analyse des informations. Comme le souligne avec à propos l'auteur, le processus de la recherche qualitative se rapproche de celui de l'intervention professionnelle; c'est donc " une méthode pouvant servir d'appui à la pratique professionnelle» (p. 15).

Écrit dans un style clair, vivant et imagé, le caractère pratique de ce livre en fait un ouvrage accessible qui devrait se révéler d'une très grande utilité pour tous ceux qui veulent s'initier à la recherche qualitative ou qui veulent puiser à ses méthodes. II reste à espérer qu'il réussira un tant soit peu à réduire le fossé qui depuis trop longtemps sépare la pratique et la recherche.

Daniel Turcotte
Université du Québec
Hull

Hull

\section{Dictionnaire de la recherche scientifique, par Richard LEFRAN- ÇOIS, Lennoxville, Les Éditions Némésis, 1991, 220 pages.}

Le Dictionnaire de la recherche scientifique, comme son nom l'indique, est un dictionnaire québécois et francophone, qui présente plus de 1400 mots ou expressions. Trois axes méthodologiques principaux ont retenu l'attention de l'auteur, soit : la philosophie des sciences (épistémologie), les méthodes et techniques d'investigation, les procédures statistiques.

Les mots et expressions recensés suivent l'ordre alphabétique, et à chacun est associée l'expression anglophone correspondante. Les renvois aux expressions analogues ou associées sont faits systématiquement et on y retrouve, à l'occasion, des synonymes et antonymes.

$C^{\prime}$ est un livre très intéressant, concis, précis et d'une utilité certaine autant pour le chercheur que pour le praticien à la quête de ce genre de précisions méthodologiques. Les définitions présentées sont très pertinentes, notamment lorsque l'on y fait ressortir la spécificité ou l'utilité de certaines d'entre elles en recherche sociale.

Un atout important, entre autres, est d'avoir joint aux définitions de nature statistique les formules correspondantes. Le lien entre chaque notion statistique et le contexte de son utilisation est également fait, ce qui est très précieux pour le chercheur social.

Il existe de fait de nombreux ouvrages de ce genre en langue anglaise, moins en français. Le secteur de l'éducation, entre autres, en a déjà à son actif. Le dictionnaire a donc l'avantage d'être québécois et surtout d'être adapté aux besoins des chercheurs sociaux. utile.

Bref, un document de référence bien structuré, pertinent, intéressant et 